\title{
Commentary: Strontium Is Released Rapidly From Agricultural Lime-Implications for Provenance and Migration Studies
}

\author{
Robert Frei* \\ Department of Geosciences and Natural Resource Management, University of Copenhagen, Copenhagen, Denmark
}

Keywords: agricultural lime, pre-historic human mobility, strontium Isotopes, soil profile, surface water, baseline, isoscape, strontium retention

\section{A Commentary on}

Strontium Is Released Rapidly From Agricultural Lime-Implications for Provenance and Migration Studies

OPEN ACCESS

by Andreasen, R., and Thomsen, E. (2021). Front. Ecol. Evol. 8:588422. doi: 10.3389/fevo.2020.588422

Edited by:

Gael Le Roux,

UMR5245 Laboratoire Ecologie Fonctionnelle et Environnement

(ECOLAB), France

Reviewed by:

Clement Pierre Bataille,

University of Ottawa, Canada

Klervia Jaouen,

UMR5563 Géosciences

Environnement Toulouse (GET), France

*Correspondence: Robert Frei

robertf@ign.ku.dk

Specialty section:

This article was submitted to Paleoecology,

a section of the journal

Frontiers in Ecology and Evolution

Received: 17 March 2021

Accepted: 19 April 2021

Published: 13 May 2021

Citation:

Frei R (2021) Commentary: Strontium Is Released Rapidly From Agricultural Lime-Implications for Provenance and

Migration Studies.

Front. Ecol. Evol. 9:681896. doi: 10.3389/fevo.2021.681896

\section{INTRODUCTION}

There is an ongoing debate about the potential effect of agricultural lime-sourced strontium (Sr) on surface waters. Strontium isotope signatures of surface waters are being used as one of several proxies to characterize the average bioavailable strontium isotope range (baseline/isoscape) of a specific geographical area. In their article, Andreasen and Thomsen (2021) conclude, based on the study of several soil profiles from a test area in Denmark which received different levels of agricultural liming during the past $\sim 100$ years, that "...Sr is as highly mobile as $\mathrm{Ca}$ is, and little is retained in organic-rich topsoils, such that Sr seeps into the underlying groundwater and nearby surface waters" and so contaminates the natural Sr isotope signature of the vadose zone. Their study is a follow up of an earlier study (Thomsen and Andreasen, 2019) in which these authors strongly criticize the use of water-based reference baselines for provenance studies of ancient humans, and go as far as to postulate "...significant overestimation of the degree of pre-historic mobility in an area, as it has in Denmark, where the overall mobility during pre-historic times was likely significantly lower than recently proposed (Frei et al., 2019)."

As outlined below, these and other conclusions are not supported by their data, as they are based on inappropriate mass balance calculations.

A central methodological detail will help the reader understand the below outlined reasoning for this. Andreasen and Thomsen (2021) applied two different procedures to the soils they studied. (1) Acetic acid leaching which releases Sr that is still contained in left over (not yet dissolved) agricultural lime. (2) Ammonium nitrate leaching, which releases exchangeable Sr adsorbed to mineral surfaces and organic matter. The sum of Sr released by both extractions should then be balanced against the total amount of Sr added by agricultural liming.

The crucial mistake lies in the fact that Andreasen and Thomsen (2021) did not balance $\mathrm{Sr}$ in their profiles against the amounts of $\mathrm{Sr}$ that were actually added over the c. 100 years to the respective soils. The massive loss of $80-100 \%$ of Sr they postulate is lost to the vadose zone is solely based on the comparison of acetic acid leachable Sr fractions in 2014 and 2019 (profile C), but does not take into consideration the large amounts of Sr from decades of liming still contained in the organic-rich soils as reflected by the ammonium 
TABLE 1 | Strontium retention percentage values in 4 different profiles studied by Andreasen and Thomsen (2021).

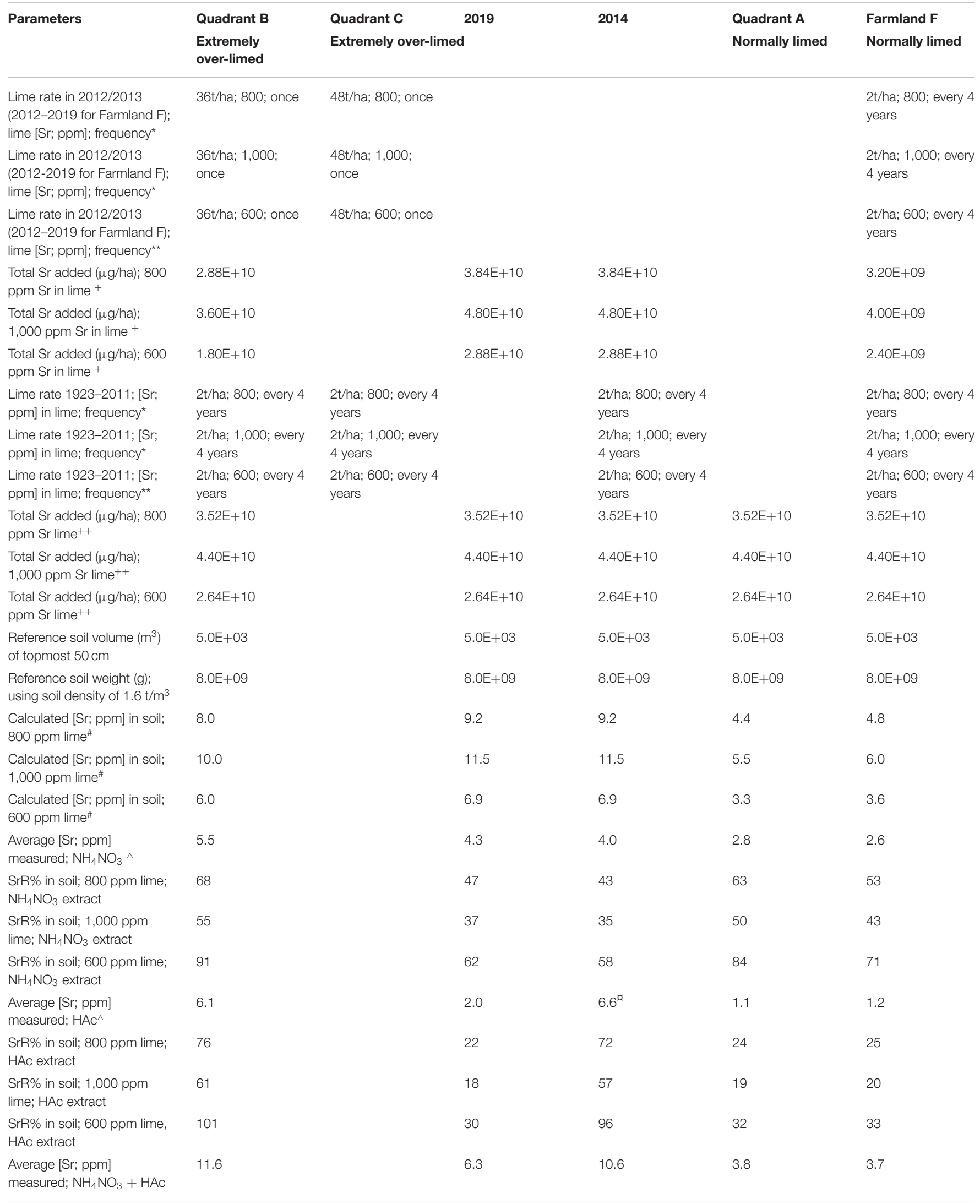


TABLE 1 | Continued

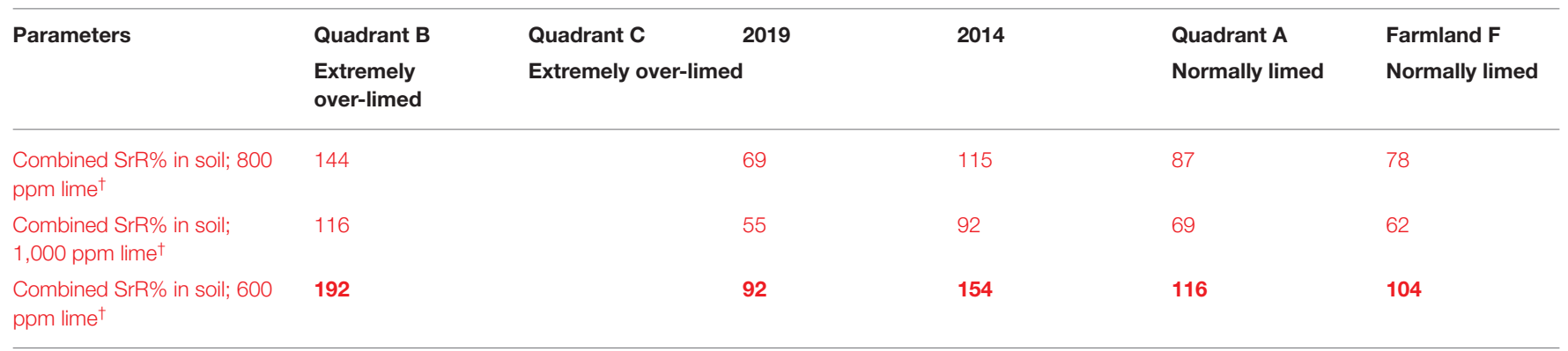

"800-1,000 ppm Sr in lime (Chalk, "Dania," U. Maastrichtian), reported by Thomsen and Andreasen (2019) and used in the mass budget calculations of Andreasen and Thomsen (2021); liming rates reported by Andreasen and Thomsen (2021).

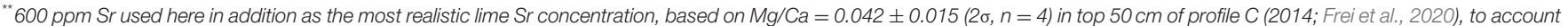
for a dolomitic component in the lime (2.5\% Mg-Chalk, "Dankalk Aggersund," Thomsen and Andreasen, 2019).

+ Total amount of Sr added via agricultural lime in 2012/2013 (during period 2012-2019 for Farmland F).

++ Total amount of Sr added via agricultural lime during period 1923-2011.

${ }^{a}$ Assuming 33 ppm of Sr measured by Frei et al. (2020) in the HAc fraction of the 5-15 cm soil interval of untilled quadrant $C$ in 2014 , distributed over the $50 \mathrm{~cm}$ thick reference soil layer.

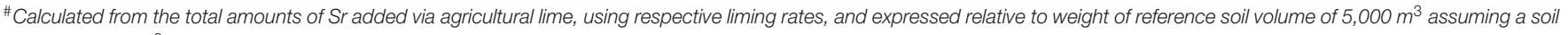
density of $1.6 \mathrm{t} / \mathrm{m}^{3}$.

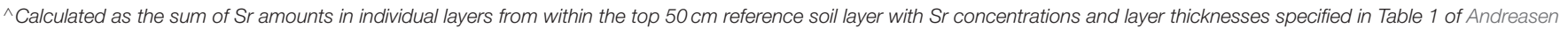
and Thomsen (2021) and in Table S1 of Frei et al. (2020), relative to the weight of the latter.

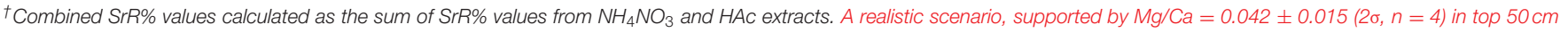
of profile C (2014; Frei et al., 2020) is highlighted in red bold letters.

$\mathrm{SrR} \%$, Strontium retention percentage; $\mathrm{NH}_{4} \mathrm{NO}_{3}$, Ammonium nitrate; HAc, Acetic acid; Sr; ppm, Strontium concentration in ppm.

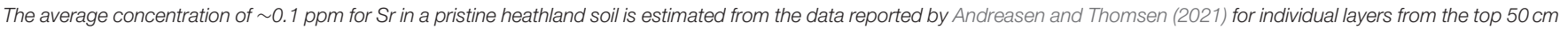
of profile $\mathrm{N}$ (top $5 \mathrm{~cm}$ mor layer excluded). This low concentration has only insignificant effects on the above mass budget calculations.

nitrate leachates. Consequently, their mass balance for profile $\mathrm{C}$ is erroneous.

\section{MASS BALANCE CALCULATIONS}

Calculations in Table 1 are based on the soil profile data published by Andreasen and Thomsen (2021) and complemented by data presented in a previous study (Frei et al., 2020) on profile $C$ in the test area representing the situation in 2014. Of the 3 profiles studied from the test area, quadrants $B$ and $C$ received extreme (and hence unrealistic) amounts of agricultural lime in 2012/2013 corresponding to an equivalent of 36 and $48 \mathrm{x}$ times, respectively, the amount conventionally added every fourth year (2t/ha) to this farmland. In contrast, profiles $A$ and $\mathrm{F}$ represent realistically limed farmland sites which received an average liming rate of $2 \mathrm{t} / \mathrm{ha}$ every 4 th year during the past $\sim 100$ years. Elevated exchangeable $\mathrm{Mg}^{2+}$ (in the top $50 \mathrm{~cm}$ ) point to a dolomitic component in the added lime. For this reason, besides using 800 and 1,000 ppm Sr for the lime, a mass budget calculation with the more realistic Sr concentration of $600 \mathrm{ppm}$ typical of a $\mathrm{Mg}$ chalk (as measured by Thomsen and Andreasen, 2019 ) is used. Mass budget values are expressed as strontium retention percentages (SrR\%) reflecting the percentages of Sr still present in the top $50 \mathrm{~cm}$ of profiles in 2019, relative to the total amount of Sr added during the last $\sim 100$ years by agricultural lime (including the massive additions in 2012/2013 to quadrants $\mathrm{B}$ and $\mathrm{C})$.

\section{DISCUSSION}

Table 1 lists SrR\% values calculated on the basis of the sum of $\mathrm{Sr}$ released by ammonium nitrate and acetic acid. These clearly imply, unlike postulated by Andreasen and Thomsen (2021), an effective retention of $\mathrm{Sr}$ derived from lime added during the last $\sim 100$ years in the topmost $50 \mathrm{~cm}$ of the studied profiles, even in quadrants that were loaded with extreme amounts of lime. Importantly, SrR\% values (using Mg chalk) for realistically limed farmlands represented by profile $\mathrm{A}$ and $\mathrm{F}$ point to complete retention of Sr.

Tilling of quadrant $\mathrm{C}$, in contrast to no tilling of quadrant $\mathrm{B}$, has led to a faster dissolution of the extreme lime load added in 2012/2013. The somewhat reduced SrR\% of this quadrant, compared to the others, likely reflects an oversaturation of lime in the soil and a related saturation of the adsorption capacity of the organic matter due to extreme liming. In this respect, profile $\mathrm{C}$, and likewise profile $\mathrm{B}$ with a similarly extreme overliming, are not representative of common farmland agricultural liming practice.

\section{CONCLUSION}

Mass balances show that most of the $\mathrm{Sr}$ added over the past $\sim 100$ years to the test field quadrants by agricultural lime is still today retained in the topmost $50 \mathrm{~cm}$ of the soils. As already concluded in Frei et al. (2020) and shown by Boyer et al. (2018), Sr is effectively and almost irreversibly adsorbed onto organic material in the soils which efficiently prevents loss of $\mathrm{Sr}$ into the vadose zone. The adsorptive capacity of organic material for $\mathrm{Sr}$ is depicted by the high $\mathrm{NH}_{4} \mathrm{NO}_{3}$-based $\mathrm{SrR} \%$ values for 2019 (Table 1). Hence, the conclusion by Andreasen and Thomsen (2021) postulating that $\mathrm{Sr}$ is rapidly released from lime into surface waters is not shown by their data. The even more far reaching conclusions that "isoscapes ... from surface waters... like Frei 
and Frei's (2011) isoscape of Denmark are inappropriate for use in provenance and mobility studies of prehistoric people" are unsupported and up front wrong. Unfortunately these misleading conclusions have caused a great deal of confusion amongst those involved in the construction of meaningful reference baselines, and particularly amongst archaeologists who see themselves thorn between very different interpretations

\section{REFERENCES}

Andreasen, R., and Thomsen, E. (2021). Strontium is released rapidly from agricultural lime-implications for provenance and migration studies. Front. Ecol. Evol. 8:588422. doi: 10.3389/fevo.2020.588422

Boyer, A., Ning, P., Killey, D., Klukas, M., Rowan, D., Simpson, A. J., et al. (2018). Strontium adsorption and desorption in wetlands: role of organic matter functional groups and environmental implications. Water Res. 133, 27-36. doi: 10.1016/j.watres.2018.01.026

Frei, K. M., Bergerbrant, S., Sjögren, K. -G., Jørkov, M. L., Lynnerup, N., Harvig, L., et al. (2019). Mapping human mobility during the third and second millennia BC in present-day Denmark. PLoS ONE 14:e0219850. doi: 10.1371/journal.pone.0219850

Frei, K. M., and Frei, R. (2011). The geographic distribution of strontium isotopes in Danish surface waters-a base for provenance studies in archaeology, hydrology and agriculture. Appl. Geochem. 26, 326-340. doi: 10.1016/j.apgeochem.2010.1 2.006 regarding the origin of some of the iconic prehistoric humans from Denmark.

\section{AUTHOR CONTRIBUTIONS}

RF has made mass balance calculations and wrote the commentary.

Frei, R., Frei, K. M., and Jessen, S. (2020). Shallow retardation of the strontium isotope signal of agricultural liming - implications for isoscapes used in provenance studies. Sci. Total Environ. 706:135710. doi: 10.1016/j.scitotenv.2019.135710

Thomsen, E., and Andreasen, R. (2019). Agricultural lime disturbs natural strontium isotope variations: Implications for provenance and migration studies. Sci. Adv. 5:eaav8083. doi: 10.1126/sciadv.aav8083

Conflict of Interest: The author declares that the research was conducted in the absence of any commercial or financial relationships that could be construed as a potential conflict of interest.

Copyright (C) 2021 Frei. This is an open-access article distributed under the terms of the Creative Commons Attribution License (CC BY). The use, distribution or reproduction in other forums is permitted, provided the original author(s) and the copyright owner(s) are credited and that the original publication in this journal is cited, in accordance with accepted academic practice. No use, distribution or reproduction is permitted which does not comply with these terms. 